\title{
The Use of Telemedicine for the Management of Hepatitis C \& the California Telehealth Network
}

\author{
Cara Torruellas, MD, MPH, ${ }^{1}$ Colette C. Rossaro, BS, ${ }^{2}$ \\ Chin-Shang $\mathrm{Li}, \mathrm{PhD}^{3}$ and Lorenzo Rossaro MD, FACP2 \\ ${ }^{1}$ Department of Internal Medicine, \\ ${ }^{2}$ Division of Gastroenterology and Hepatology, and Center for TeleHealth Technology, \\ University of California Davis Health System, Sacramento, California, \\ ${ }^{3}$ Department of Public Health Sciences, Division of Biostatistics, University of California, \\ Davis, California, \\ USA
}

\section{Introduction}

Despite a plateau in the incidence of acute hepatitis C infection since 2003 (Daniels, 2009), chronic hepatitis $\mathrm{C}$ virus (HCV) infection continues to pose a significant public health problem with a large cost burden to society. HCV is the most common blood-borne infection in the US with an estimated 3.2 million chronically infected people nationwide (Daniels, 2009). HCV is the leading cause of chronic liver disease and a major cause of hepatocellular carcinoma in the US with an estimated 8,000 to 13,000 deaths annually (Daniels, 2009; Wise et al., 2008; Armstrong et al., 2006).

Injection drug use continues to be the main risk factor leading to HCV infection. The peak prevalence occurs among adults aged 40 to 49 years with individuals of lower socioeconomic status bearing a disproportionate burden compared with other groups (Daniels, 2009; Armstrong et al., 2006). The majority of liver transplants in this country occur in patients with cirrhosis due to HCV (Verna \& Brown, 2006; Freeman et al., 2008). It is estimated that the associated total direct and indirect cost of $\mathrm{HCV}$ associated cirrhosis and hepatocellular carcinoma is greater than $\$ 5$ billion each year (Leigh et al., 2001).

In California alone, an estimated 600,000 persons have been exposed to HCV and about 450,000 Californians are living with chronic HCV. Racial disparities in infection rates exist with African Americans having the highest observed rate of $\mathrm{HCV}$ infection among all racial and ethnic groups. The prevalence of $\mathrm{HCV}$ infection among African Americans living in California is estimated at 3.2\%, among Latinos, $2.1 \%$ and among Caucasians, $1.5 \%$ (CDC, 1998).

\section{Closing the gap of access to specialty care}

Prior studies have shown that HCV patients without access to a specialist are less likely to be treated (Rocca et al., 2004). This is significant from a clinical and public health standpoint because almost half of patients treated with the current standard of care (6-18 months of therapy with pegylated interferons and ribavirin) achieve long term cure with a resultant improvement of liver-related mortality rate that approximates the one experienced in the general population (Simin et al., 2007; Veldt et al., 2007; Kasahara et al., 2004). 
Rural communities are particularly affected by the lack of access to specialty care (Yawn et al., 2002; Rossaro et al., 2008). Telemedicine consultation offers the potential to increase access to specialists in remote and underserved areas. Increasingly, primary care providers (PCPs) in remote areas are being called upon to diagnose and treat patients with $\mathrm{HCV}$. Unfortunately, many PCPs are unprepared to evaluate and manage the complexity of patients with chronic HCV and practice patterns are highly variable. Few rural practitioners have experience with the complex mental health and substance abuse issues that are common among patients with hepatitis C infection (Arora et al., 2010). In addition, they may perceive greater challenges when managing treatment side effects of pegylated interferons and ribavirin (depression, thrombocytopenia, neutropenia, anemia, GI side effects and skin rash). Optimal management of $\mathrm{HCV}$ infection requires consultation with highly trained specialists or academic institutions with dedicated hepatologists.

Furthermore, it can be difficult for patients with HCV infection living in remote or underserved areas to access specialists. Often patients are required to travel long distances to academic centers that offer specialty care, experience long wait times to see specialists at these centers, and may not be able to schedule follow up visits in a timely manner due to the high volume of patient care at these centers. While undergoing treatment for HCV infection, close monitoring and follow up with a specialist and/or close communication between a PCP and specialist is essential due to the potentially life threatening side effects of interferon and ribavirin. These factors may impede patients in remote areas from initiating treatment for HCV. Table 1 lists the different barriers to care of HCV in rural areas.

Barriers to the Management of HCV in Rural Areas

- Access to specialists

- Distance to clinic

- Low socioeconomic status
- Lack of transportation

- $\quad$ Limited education of providers

Table 1. A list of barriers to HCV management that patients in rural areas experience

Telemedicine can close the gap of access to specialty care and provide clinical decision making support to PCPs with regard to best practice treatment strategies for managing HCV patients. In the last ten years, we have provided consultations to patients with HCV via telemedicine at about 50 different locations throughout California. Our telemedicine sites have included primary clinics in rural areas with a high prevalence of HCV and low socioeconomic status as well as correctional facilities.

\section{Use of telemedicine consultation for the management of HCV patients}

Telemedicine is the use of high speed, wide band width transmission of digitized signals in conjunction with computers to provide an audio-visual interaction in real time between a patient and physician who are physically separated. Telemedicine is an effective tool to improve access for patients with HCV in underserved areas. In addition, the presence of the PCP in the room with the patient provides educational opportunities for the provider and the patient and improves the overall quality of patient care.

Telemedicine offers a unique opportunity for real time interactions among a triad of individuals (Figure 1): the patient, in need of specialty care, the PCP who actively participates during the consultation, and the specialist, who provides consultation services and education in management to both patient and PCP simultaneously. 


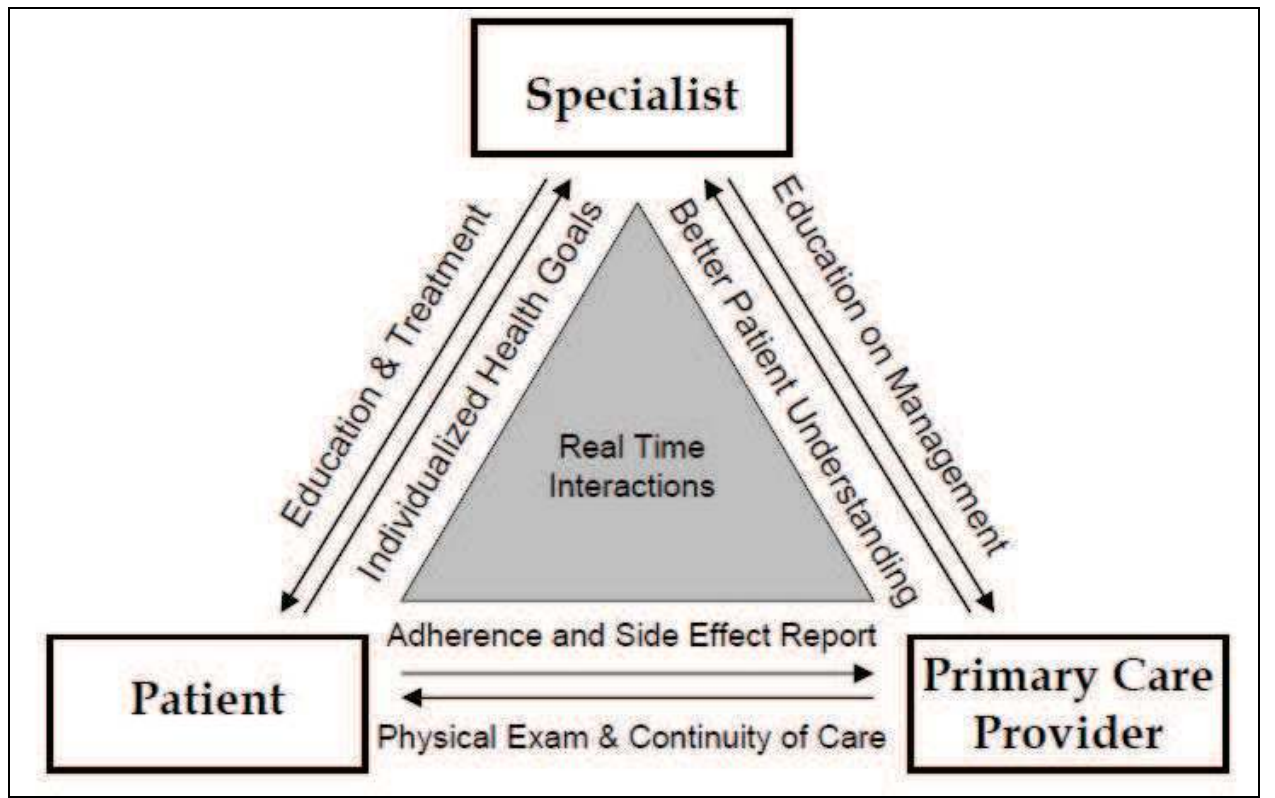

Fig. 1. Telemedicine Triad: patient, PCP, and specialist with multidirectional interactions in real time, providing care and education.

In a recent retrospective review of our data (Rossaro et al., 2008), we found a surprisingly high severity of disease in a difficult to treat population in a rural area in California (Figure 2 and Table 2). From 2000-2007, we provided consultations for 103 patients with hepatitis C living in small California rural communities with high rates of poverty and a high incidence of HCV. Of these patients, approximately half (37\% Stage $4+12 \%$ Stage $3=49 \%)$ had advanced fibrosis, and $64 \%$ had never undergone therapy with interferon and ribavirin. Twenty-three percent of the patients were candidates for therapy. The most common contraindication to therapy was the severity of their disease and the risk of decompensation

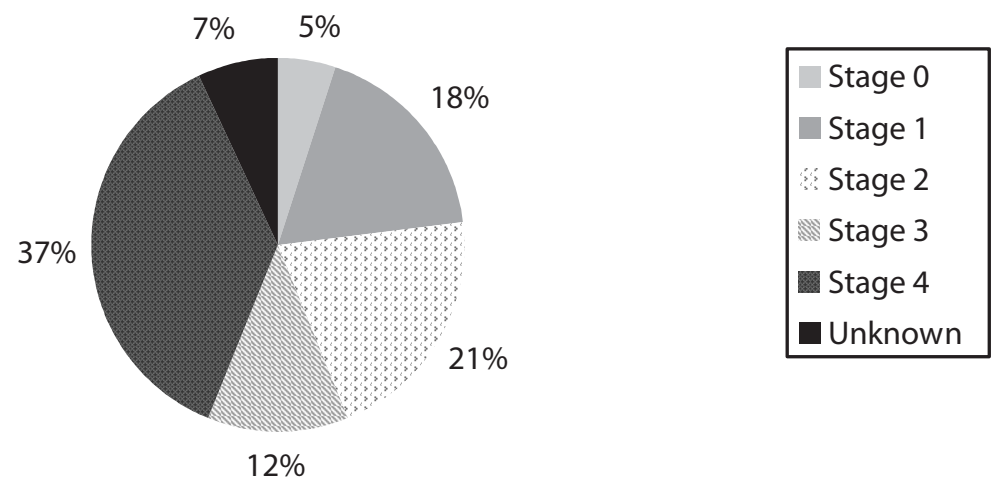

Fig. 2. Stage of Fibrosis of patients evaluated by Telemedicine according to the Knodell score (Rossaro et al., 2008) 


\begin{tabular}{|c|c|}
\hline Male & $47 \%$ \\
\hline Female & $53 \%$ \\
\hline Weight (mean) & $88.46 \mathrm{~kg}$ \\
\hline Age (mean) & 49 yrs \\
\hline \multicolumn{2}{|l|}{ Patient Insurance } \\
\hline No insurance & $6 \%$ \\
\hline County & $25 \%$ \\
\hline Medi-Cal & $61 \%$ \\
\hline Medicare & $6 \%$ \\
\hline Private & $2 \%$ \\
\hline \multicolumn{2}{|l|}{ Viral genotype } \\
\hline 1 & $71 \%$ \\
\hline 2 & $11 \%$ \\
\hline 3 & $15 \%$ \\
\hline 4 & $2 \%$ \\
\hline 6 & $1 \%$ \\
\hline HCV Viral load > 450,000 IU & $37 \%$ \\
\hline Advanced liver fibrosis & $49 \%$ \\
\hline $\begin{array}{l}\text { Model for End Stage Liver Disease } \\
(\text { MELD })>12\end{array}$ & $19 \%$ \\
\hline Treatment naïve & $64 \%$ \\
\hline Treatment recommended & $23 \%$ \\
\hline
\end{tabular}

Table 2. Characteristics of Patients evaluated by Telemedicine (Rossaro et al., 2008)

during treatment due to advanced cirrhosis. Fifteen patients were evaluated for liver transplant. Two patients were listed for transplantation but neither survived long enough to receive a liver.

Our data suggest that a large number of patients with hepatitis $C$ and advanced liver disease are living in rural communities, some of whom may need treatment or liver transplant. Telemedicine is an effective tool for identifying and treating patients with hepatitis $C$ who live in rural communities who may otherwise go untreated or not listed for liver transplantation.

\section{Improving practitioner hepatitis $C$ knowledge by video conferencing}

Telemedicine can also be utilized to provide education to practitioners regarding HCV. In a recent study, we compared the impact of multipoint videoconferencing versus standard lecturing on level of knowledge attainment in different groups of PCPs including physicians, nurse practitioners, physician assistants, and registered nurses (Rossaro et al., 2007).

The hypothesis was that the educational impact of teaching through telemedicine is comparable to the traditional didactic method. The aim was to provide participants with clinically relevant information and knowledge about the natural history, diagnosis, and management of $\mathrm{HCV}$. Improved knowledge was scored from a 10-item questionnaire administered before and after the educational intervention. For all practitioners combined, the videoconferencing group scored significantly lower on the pretest than the standard lecturing group (Table 3).

All three types of learners improved their knowledge scores following intervention in both methods. However the videoconferencing group scored significantly higher on the posttest 


\begin{tabular}{|l|c|c|c|}
\hline & \multicolumn{2}{|c|}{ All Providers (MDs, NPs/PAs, RNs) } & \\
\cline { 1 - 3 } & $\begin{array}{c}\text { Videoconferencing } \\
\mathrm{n}=62\end{array}$ & $\begin{array}{c}\text { Standard Lecture } \\
\mathrm{n}=113\end{array}$ & p value ** \\
\cline { 1 - 3 } Pretest Score * & 4.3 & 4.9 & $<0.05$ \\
\hline Posttest Score * & 8.7 & 7.9 & $<0.001$ \\
\hline Score Improvement & 4.4 & 3.0 & $<0.001$ \\
\hline
\end{tabular}

Legend: MDs, Medical Doctors; NPs, Nurse Practitioners; PAs, Physician Assistants; RNs, Registered Nurses. * Pre and Post-test scores range from 0-10 items correct. ** T-test analysis

\section{Table 3. Knowledge Scores: Videoconferencing Method vs. Standard Lecture}

and had a significantly greater score improvement. Nurses showed the greatest improvements, correctly answering an average of four to five more questions following the video conferencing educational intervention. The results of this study indicate that video conferencing is equivalent, if not better, than standard continuing medical education. Video conferencing can potentially improve clinician education regarding the history, diagnosis, and management of $\mathrm{HCV}$, thereby making a substantial impact on the clinical course of patients with this condition. In addition, video conferencing has the potential to eliminate the financial and geographic barriers to professional education for rural practitioners.

\section{Hepatitis $\mathrm{C}$ in the correctional system}

$\mathrm{HCV}$ infection is rampant within the correctional system. A study of about 4500 inmates entering the Californian correctional system found that $39 \%$ of males and $53 \%$ of females were chronically infected. This is becoming a serious concern to public health officials, health care providers and policy makers. Infected inmates may continue to engage in high risk behaviors and infect others while in custody, they may transmit the disease to people in the community to which they are released and the cost of providing care to HCV infected inmates with chronic liver disease or hepatocellular carcinoma is rising (Ruiz et al., 1999). Subsequent studies have reported the prevalence of $\mathrm{HCV}$ to be $34 \%$ and independently correlated with age, history of intravenous drug use, cumulative time of incarceration, male biological sex > female, and history of sex with a male intravenous drug user. (Fox et al., 2005)

$\mathrm{HCV}$ has also been implicated in the high prevalence of end stage liver disease in state prisons. A study from Texas with more than 370,000 prisoners during a period of 3.5 years found the prevalence of end stage liver disease to be as high as 131 per 100,000 prisoners with 57 per 100,000 dying during the study period due to complications of end stage liver disease. The estimate of mortality for end stage liver disease in the Texas prison population was approximately 3 times higher than that of the general population. Risk of high mortality were found in the following groups: Hispanics, greater than 50 yrs of age, HIV monoinfected, HCV monoinfected, HCV-HIV coinfected (Baillargeon et al., 2007).

It has been advocated that inmate education and counseling are important in preventing $\mathrm{HCV}$ infection as well as HIV and hepatitis B infection. Counseling should be culturally appropriate and consistent with the learning skill of the inmate. Prevention strategies should be designed to encourage voluntary behavior change and effective risk reduction.

Finally it has been advocated that an assessment of the risk factor profile of all inmates entering the correctional system should be conducted (Ruiz et al. 1999)

The enormous cost of organ transplantation and management of end stage liver disease are serious challenges to the health care budgets of most prison systems. Consequently, it is 
crucial that correctional health care programs expand $\mathrm{HCV}$ treatment and infection prevention strategies. (Baillargeon et al., 2007) It is well known that treatment of HCV early enough, before end stage liver disease and liver cancer occur, is highly cost effective. While HCV therapy appears expensive, many cost effectiveness analysis suggest that treatment with Pegylated interferon and ribavirin provides value comparable to many well accepted medical interventions (Bhavesh \& Wong, 2006).

A study from the Medical College of Virginia, utilizing telemedicine consultation services, showed that $\mathrm{HCV}$ therapy can be effectively managed in correctional facilities with response rates similar to, if not better than, the non-inmate population (Sterling et al. 2004). This study included a retrospective analysis of 59 consecutive inmates who received $\mathrm{HCV}$ therapy under direct observation with standard interferon (non pegylated, 3 MIU TIW and ribavirin 1000$1200 \mathrm{mg}$ per day). As expected, sustained virological response (cure) was higher in Caucasians (41\%) compared with African Americans (28\%), although the differences were not statistically significant. Even more so, when the analysis was concentrated on HCV genotype 1 alone, Caucasians and African Americans performed similarly (33\% vs. 29\%). The above results are remarkable given the fact that non-pegylated based therapy was utilized and partly related to the high adherence allowed by direct observation of therapy.

Since year 2000, at the UC Davis Center for Health Technology, we have provided hundreds of telemedicine consultations and videoconferencing educational events with several correctional facilities throughout California. We found inmates to be highly motivated to initiate treatment and their compliance while on treatment has been excellent. The drop out rate while on treatment appears to be similar to that of the non-inmate population (about $10 \%$ ) (Unpublished observations). One key factor for successful therapy is continuity of care once therapy is initiated. It is desirable that the inmate not be transferred to another facility during treatment (6-18months).

\section{Next steps: The California telehealth network}

The California Telehealth Network (CTN) (California Telehealth Network Website, 2010) was established in 2007 with a \$22.1 million grant from the Federal Communications Commission's Rural Health Care Pilot Program (RHCPP) and matching funds of \$3.6 million from the California Emerging Technology Fund. CTN is a statewide dedicated health care broadband network, developed to ensure that California communities, especially rural communities, have access to a wide range of telemedicine and eHealth activities. CTN will provide the connectivity necessary to access high quality, collaborative health services, continuing education, research and peer networking activities. The connectivity provided by the CTN will create new telecommunications infrastructure, eventually allowing California's rural communities to access a broad range of technology-enhanced services to improve the quality of health care services in California.

Collectively, the Federal Communications Commission award and other new resources will help California develop an effective, sustainable and forward-looking telehealth network, focusing first on rural communities and subsequently expanding to serve increasing numbers of California health providers in both rural and urban areas. Over the course of the project, the new network will connect more than 860 rural sites with each other, and with a network of specialty providers at academic medical centers and other nonprofit and for-profit health providers statewide. Strong emphasis will be placed on infrastructure development, telecommunications quality and technical support. The University of California (UC), with the UC Davis Health System serves as the lead technical and operational entity for the CTN. 
The California Telehealth Network is intended to improve access within rural and underserved areas to high quality, collaborative health services and to make new networking capability available for more California health providers. The CTN will link California providers to a nationwide broadband network dedicated to health care.

\section{Current research}

New models for delivery of telemedicine delivery have been developed and offer promising delivery of specialist services to remote and underserved areas. One model, The Extension for Community Healthcare Outcomes (ECHO) Model was developed by the University of New Mexico Health Sciences Center to deliver complex specialty medical care to underserved populations (Arora et al., 2007; Arora et al., 2010). The ECHO model was first developed for the management of HCV. ECHO provides health care delivery and clinical education to rural primary care practitioners via video conferencing (Arora et al. 2007). The ECHO model uses "telehealth technology, best practice protocols, and case-based learning" to train and support primary care providers in the development of their knowledge and selfefficacy for managing chronic diseases (Arora et al., 2010). Initial survey data of the project have demonstrated a significant improvement in provider knowledge, self-efficacy, and professional satisfaction through participation in ECHO HCV clinics (Arora et al., 2010). However, no patient outcome data are yet available for this project.

In 2007, we completed a retrospective chart review of 103 telemedicine patients with HCV from Peach Tree Clinic in Marysville, California to characterize the patient population seen in rural clinics. The study found that there is a need for more consultation and education of primary care providers for patients living with $\mathrm{HCV}$ in rural communities, and telemedicine appears to be an effective modality for increasing access to liver specialists and education (Rossaro et al., 2008).

Telemedicine consultation offers the potential to increase access to specialists in remote and underserved areas and has been successfully utilized in the field of trauma with non-inferior outcomes for injured patients treated at rural centers (Duchesne et al., 2008). To our knowledge, however, no studies have examined the utility, safety or efficacy of telemedicine for the management of chronic diseases in terms of patient outcomes.

\section{Future research}

\subsection{Next steps}

Our next research study will attempt to fill this telemedicine HCV patient outcomes research gap. We will expand our previous observational study and compare actual patient outcomes with $\mathrm{HCV}$ patients treated via telemedicine consultation at Peach Tree Clinic and other telemedicine sites as compared to standard hepatology office practice.

\subsection{Study methods}

We will perform a retrospective analysis, in two phases, using standard chart review of $\mathrm{HCV}$ patients seen at all available telemedicine sites and the UC Davis Gastroenterology (UCD GI) Clinic between the years 2008 and 2010. Our initial retrospective cohort study will be a descriptive comparison of telemedicine patients vs. traditional visit patients without matching to characterize group differences in these patient populations. We will attempt to 
identify general group differences by comparing the following variables between groups: mean age at initiation of therapy, gender distribution, ethnicity distribution, hepatitis $\mathrm{C}$ genotype, stage of fibrosis, viral load at baseline, 4 , and 12 weeks after the start of therapy to assess for rapid and early virological response, rates of therapy completion and rates/types of side effects experienced by patients. Our goal number of cases for each comparison group is approximately 50 , for a total of 100 patients for this pilot study.

As a second phase of investigation, we will conduct a case-control study matching telemedicine cases with traditional visit controls by age, gender, ethnicity, Hepatitis C genotype and stage of fibrosis in order to compare outcomes of early virological response at 12 weeks and side effect profiles of patients treated with interferon and ribavirin. Our final study will include an anticipated total of 100 controls and 100 telemedicine cases in order to achieve a power analysis of $80 \%$.

Inclusion criteria for study subjects will include: a) age 18-75 years; $b$ ) hepatitis $C$ positive by PCR; c) treatment naïve; and d) referred for HCV treatment by primary care provider. Exclusion criteria will include a) patients active substance use; b) psychiatric diagnosis of uncontrolled clinical depression; c) co-infection with HBV or d) co-infection with HIV.

Once all cases are identified and inclusion criteria are met, we will match each case with at least one control patient from the UCDMC based on the following variables: a) age, $<50$ years or $>=50$ years; b) gender; c) ethnicity/race ; d) hepatitis $C$ genotype, type 1 vs. non- 1 ; and e) stage of fibrosis (0-2 vs. 3-4).

Once all cases and controls are matched on the above variables, we will collect outcome data on the following variables: a) rapid virologic response at 4 weeks (yes or no); b) viral load at 4 weeks; c) early virologic response at 12 weeks (yes or no); d) viral load at 12 weeks; e) completion of therapy (yes, no or in progress); f) termination of treatment due to side effects (yes or no); and g) side effects experienced.

We will collect data on each patient at 4 and 12 weeks that will allow us to determine treatment response and track side effects which include anemia, thrombocytopenia, neutropenia, weight loss, rash, fatigue, GI upset and depression. This data will be collected, coded using a standard coding system and entered into a standard database system. This patient database will be encrypted with a password as it is developed and accessible only to approved research project members for data entry. Once all data has been collected, this data set will be converted into a non-identifiable database and the original encrypted database will be kept on a CD ROM in a locked file cabinet inside a locked office.

\subsection{Statistical considerations}

We will consider whether a patient has an early virological response $(70 \%$ predictive of sustained virological response 24 weeks after completion of a 48 week course of treatment) after completing therapy for 12 weeks, measured via PCR as the primary endpoint (outcome), which is a binary outcome (response) variable. Let $\Pi_{1}$ and $\Pi_{2}$ be the early virological response rates in the traditional office visit group and the telemedicine group, respectively. We want to test the null hypothesis of no difference in the early virological response rate between the two groups (cases and controls), i.e., $\Pi_{1}=\Pi_{2}(\mathrm{OR}=1)$, versus the alternative hypothesis that there is a difference in the early virological response rate between the two groups, i.e., $\Pi_{1} \neq \Pi_{2}(\mathrm{OR} \neq 1)$. Then, a total of 100 patients (50 patients in each group) can provide the power of $12.3 \%$ to detect the difference of $10 \%\left(\Pi_{1}=60 \%, \Pi_{2}=\right.$ $50 \%)(0.5$ in terms of OR) in the early virological response rate between the two groups by using two-sided Fisher's exact test at significance level of 5\%. However, a total of 200 
patients (100 patients in each group) can provide the power of $80 \%$ to detect the difference of $11.6 \%\left(\Pi_{1}=60 \%, \Pi_{2}=48.4 \%\right)(0.568$ in terms of OR)] in the early virological response rate between the two groups by using two-sided Fisher's exact test at significance level of $5 \%$.

\subsection{Statistical analysis plan}

Cohort comparison group demographics and clinical features will be analyzed qualitatively and quantitatively. A Fisher's exact test will be used to compare each of the dichotomous (or polytomous) outcome variables of interest between the two groups. As secondary analyses, logistic regression will be used to control for possible confounding factors while comparing a category variable between the two groups in which the group variable will be treated as a predictor.

\subsection{Anticipated results}

We anticipate that our study will demonstrate non-inferiority in terms of early virological response, treatment failures and side effect profile in patients seen through telemedicine consultations compared to regular office visits.

\section{Conclusion}

Telemedicine consultation offers the potential to increase access to specialists in remote and underserved areas and may be an effective tool for identifying and treating patients with $\mathrm{HCV}$ who live in rural communities who may otherwise go untreated and progress to serious liver diseases, such as cirrhosis and cancer. It offers a unique opportunity of real time interactions among the patient, the $\mathrm{PCP}$, and the specialist. Telemedicine can also be utilized to provide education to practitioners regarding $\mathrm{HCV}$ and provide clinical support to primary care providers in the complex management of $\mathrm{HCV}$ patients. Future outcomes research is needed to examine the safety and efficacy of telemedicine for the management of chronic diseases such as HCV.

\section{References}

Armstrong, G, Wasley, A, Simard, E, et al. (2006). The prevalence of hepatitis C virus infection in the United States, 1999 through 2002. Ann Intern Med 2006;144:705-14.

Arora, S, Geppert, C, Kalishman, S, Dion, D, Pullara, F, et al. (2007). Academic Health Center Management of Chronic Diseases through Knowledge Networks: Project ECHO. Academic Medicine, February 2007;82(2):154-60.

Arora, S, Kalishman, S, Thornton, K, Dion, D, Murata, G et al. (2010). Expanding Access to Hepatitis C Virus Treatment-Extension for Community Healthcare Outcomes (ECHO) Project: Disruptive Innovation in Specialty Care. Hepatology 2010;52:11241133.

Baillargeon, J, Soloway, R, Paar, D, Giordano, T, Murray, O, Grady, J, Williams, B, Pulvino, J, Raimer, B. (2007) End-Stage Liver Disease in a State Prison Population. Ann Epidemiol. Oct 2007; 17(10): 808-813.

Bhavesh, S. \& Wong, J. (2006). The Economics of Hepatitis C Virus. Clin Liver Dis 2006;10: 717-734.

California Telehealth Network Website (2010). http://www.caltelehealth.org/, accessed $10 / 02 / 2010$. 
Centers for Disease Control and Prevention (1998). Recommendations for prevention and control of hepatitis C virus (HCV) infection and HCV-related chronic disease. MMWR Recomm Rep, 1998;47(RR-19):1-39.

Daniels, D. (2009). Surveillance for acute viral hepatitis - United States, 2007. Morbidity and mortality weekly report. CDC surveillance summaries [1546-0738] volume: 58 issue: 3 page: $1-27$.

Duchesne, J, Kyle, A, Simmons, J, Islam, S, Schmieg, R, Olivier J, McSwain, N. (2008). Impact of Telemedicine Upon Rural Trauma Care. Journal of Trauma-Injury Infection $\mathcal{E}$ Critical Care. January 2008. 64 (1):92-98.

Fox, R, Currie, S, Evans, J, Wright, T, Tobler, L, Phelps, B, Busch, M, Page-Shafer, K. (2005). Hepatitis C Virus Infection Among Prisoners in the California State Correctional System. Clin Infect Dis. Jul 2005, 41(2): 177-186.

Freeman, R, Steffick, D, Guidinger, M, Farmer, D, Berg, C, Merion, R. (2008). Liver and intestine transplantation in the United States, 1997-2006. Am J Transplant 2008;8:958976.

Kasahara, A, Tanaka, H, Okanoue, T, Imai, Y, Tsubouchi, H, Yoshioka, K, et al. (2004). Interferon treatment improves survival in chronic hepatitis $C$ patients showing biochemical as well as virological responses by preventing liver related death. J Viral Hepat 2004;11:148-156.

Leigh, J, Bowlus, C, Leistikow, B, Schenker, M. (2001). Cost of hepatitis C. Arch Internal Med 2001; 161:2231.

Rocca, L, Yawn, B, Wollan, P, Kim, W. (2004). Management of patients with hepatitis C in a community population: Diagnosis, discussions, and decisions to treat. Ann Fam Med 2004;2:116-124.

Rossaro, L, Tran T, Ransibrahmanakul K, Rainwater J, Csik G, Cole S, Prosser C, Nesbitt T, (2007) Hepatitis C Videoconferencing: The Impact on Continuing Medical Education for Rural Healthcare Providers. Telemedicine and e-Health. June 2007, 13 (3): 269-277.

Rossaro, L, Aoki, C, Yuk, J, Prosser, C, Goforth, J, Martinez, F. (2008). The Evaluation of Patients with Hepatitis C Living in Rural California via Telemedicine. Telemedicine and e-Health. December 2008, 14(10): 1127-1129.

Ruiz, J, Molitor, F, Sun, R, Mikanda, J, Facer, M, Colford, J, Rutheford, G, Ascher, M., (1999) Prevalence and Correlates of Hepatitis C Virus Infection Among Inmates Entering the California Correctional System. West J Med. 1999, 170: 156-160.

Simin, M, Brok, J, Stima,c D, Gluud, C, Gluud, L. (2007) Cochrane systematic review: pegylated interferon plus ribavirin vs. interferon plus ribavirin for chronic hepatitis C. Aliment Pharmacol Ther 2007;25:1153-1162.

Sterling, R, Hofmann, C, Luketic, V, Sanyal, A, Contos, M, Mills, A, Shiffman, M. (2004) Treatment of Chronic Hepatitis C Virus in the Virginia Department of Corrections: Can Compliance Overcome Racial Differences to Response? Am J Gastroenterol. May 2004; 99(5): 866-872.

Veldt, B, Heathcote, E, Wedemeyer, H, Reichen, J, Hofmann, W, Zeuzem, S, et al.(2007). Sustained virologic response and clinical outcomes in patients with chronic hepatitis C and advanced fibrosis. Ann Intern Med 2007;147:677-684.

Verna, E. \& Brown, R. (2006). Hepatitis C and liver transplantation. Clin Liver Dis 2006. 10:919.

Wise, M, Bialek, S, Finelli, L, Bell, B, Sorvillo, F (2008). Changing trends in hepatitis Crelated mortality in the United States, 1995-2004. Hepatology 2008;47:1128-1135.

Yawn, B, Wollan, P, Gazzuola, L, Kim, W. (2002). Diagnosis and 10-year follow-up of a community-based hepatitis C cohort. J Fam Pract 2002;51:135-140. 


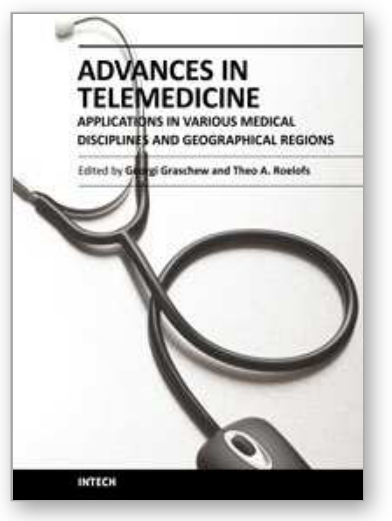

\author{
Advances in Telemedicine: Applications in Various Medical \\ Disciplines and Geographical Regions \\ Edited by Prof. Georgi Graschew
}

ISBN 978-953-307-161-9

Hard cover, 296 pages

Publisher InTech

Published online 22, March, 2011

Published in print edition March, 2011

Innovative developments in information and communication technologies (ICT) irrevocably change our lives and enable new possibilities for society. Telemedicine, which can be defined as novel ICT-enabled medical services that help to overcome classical barriers in space and time, definitely profits from this trend. Through Telemedicine patients can access medical expertise that may not be available at the patient's site. Telemedicine services can range from simply sending a fax message to a colleague to the use of broadband networks with multimodal video- and data streaming for second opinioning as well as medical telepresence. Telemedicine is more and more evolving into a multidisciplinary approach. This book project "Advances in Telemedicine" has been conceived to reflect this broad view and therefore has been split into two volumes, each covering specific themes: Volume 1: Technologies, Enabling Factors and Scenarios; Volume 2: Applications in Various Medical Disciplines and Geographical Regions. The current Volume 2 is structured into the following thematic sections: Cardiovascular Applications; Applications for Diabetes, Pregnancy and Prenatal Medicine; Further Selected Medical Applications; Regional Applications.

\title{
How to reference
}

In order to correctly reference this scholarly work, feel free to copy and paste the following:

Cara Torruellas, Colette C. Rossaro, Chin-Shang Li and Lorenzo Rossaro (2011). The Use of Telemedicine for the Management of Hepatitis $C$ \& the California Telehealth Network, Advances in Telemedicine: Applications in Various Medical Disciplines and Geographical Regions, Prof. Georgi Graschew (Ed.), ISBN: 978-953-307-1619, InTech, Available from: http://www.intechopen.com/books/advances-in-telemedicine-applications-in-variousmedical-disciplines-and-geographical-regions/the-use-of-telemedicine-for-the-management-of-hepatitis-c-thecalifornia-telehealth-network

\section{INTECH}

open science | open minds

\author{
InTech Europe \\ University Campus STeP Ri \\ Slavka Krautzeka 83/A \\ 51000 Rijeka, Croatia \\ Phone: +385 (51) 770447 \\ Fax: +385 (51) 686166 \\ www.intechopen.com
}

\author{
InTech China \\ Unit 405, Office Block, Hotel Equatorial Shanghai \\ No.65, Yan An Road (West), Shanghai, 200040, China \\ 中国上海市延安西路65号上海国际贵都大饭店办公楼 405 单元 \\ Phone: +86-21-62489820 \\ Fax: $+86-21-62489821$
}


(C) 2011 The Author(s). Licensee IntechOpen. This chapter is distributed under the terms of the Creative Commons Attribution-NonCommercialShareAlike-3.0 License, which permits use, distribution and reproduction for non-commercial purposes, provided the original is properly cited and derivative works building on this content are distributed under the same license. 